\title{
Extent of Healthcare Provider Adherence to National Health Insurance Scheme (NHIS) Operational Guidelines: The Nigeria Experience
}

\author{
Ikechukwu Vincent Obi (Corresponding Author) \\ Department of Health Administration and Management, University of Nigeria, Enugu \\ campus, Enugu, Nigeria. E-mail: ivcobi@yahoo.com
}

Ijeoma Lewechi Okoronkwo

Department of Nursing Services, University of Nigeria, Enugu campus, Enugu, Nigeria.

E-mail: ijeoma.okoronkwo@unn.edu.ng

\section{Emmanuel Chukwunonye Azuike}

Department of Community Medicine, Chukwuemeka Odumegwu Ojukwu University,Awka, Anambra, Nigeria. E-mail: emmanazuike@yahoo.com

\section{Kamtoochukwu Maduneme Obi}

Aguata Diocesan Center for Community Health and Development, Ekwulobia, Anambra, Nigeria. E-mail: kamtoobi@yahoo.com.

\section{Ifunanya Rosemary Obi}

Department of Physical and Health Education, Federal College of Education (Technical), Umunze, Anambra, Nigeria. E-mail: ifunanyakamtoo@gmail.com

Received: Aug. 18, 2019 Accepted: Sep. 16, 2019 Online published: Sep. 19, 2019

doi:10.5296/jpag.v9i3.15279 ＵRL: https://doi.org/10.5296/jpag.v9i3.15279

\begin{abstract}
The main objective of the National health insurance programme is to improve the health status of the populace in Nigerians. The healthcare provider provision of services in the
\end{abstract}


programme has become a source of worry to government and other stakeholders. This study therefore sets out to examine the extent of healthcare provider adherence to NHIS operational guidelines. Design/Methodology: This is a cross-sectional survey using a questionnaire method. Sample size was calculated (demand side) using G-power 3.1 software and (supply side) Cochran formular and the calculated sample sizes were 1435 and 46 respectively. Multistage sampling technique was applied. Variables were analyzed using descriptive and Ttest statistics with SPSS version 25. Result: Out of the 1435 enrollees $80 \%$ disagreed that providers provide laboratory services. Also, $91 \%$ of them disagreed that providers provide prescribed drugs. In contrast, both the enrollee (67\%) and providers $(69 \%)$ agreed that providers are polite while providing services. The Test value was set at $75 \%$. The calculated $\mathrm{T}$ value for operational guideline for enrollees was $70.81(\mathrm{p}<0.05)$ on the opinion of the enrollees on extent of provider provision of services. The calculated T-value for operational guideline for providers was $2.40(\mathrm{p}<0.05)$ on the opinion of providers on the provision of services. Conclusion: The evidence from this study have identified areas in the service provision to be addressed by policy makers and in contrast showed that both the enrollees and providers agreed overall that the healthcare providers adhere to NHIS operational guideline.

Keywords: adherence, healthcare provider, enrollee, national health insurance programme, Nigeria

\section{Introduction}

The combination of law of helping one another with that of bringing all the contributions made by members of a pool together to buy healthcare is the principle underpinning the health insurance programme in Nigeria. The main objective of the programme is to improve the health status of the populace in Nigerians using five major stakeholders (Payer, Regulator, Hmo, Healthcare provider and Enrollee) and this will invariably contribute to the existing strategies of reducing poverty as envisioned by the government (Adibe, Udeogaranya \& Ubaka, 2011; Awosika, 2012).

The healthcare providers have roles and responsibilities in the National health insurance scheme (NHIS). According to NHIS (2015) operational guideline, these roles and responsibilities include provision of services as agreed with the HMOs in the benefit package. These services include offering 24 hour services, laboratory services, emergency services, admission services, referral of enrollees and provision of prescribed medications. Another role and responsibility of healthcare provider is to ensure enrollee satisfaction and it includes being polite to enrollees, showing empathy, understanding enrollee plight and attending to enrollees promptly.

Healthcare providers exert their influence by dictating the nature and quality of treatment needed by enrollees. Similarly, the perception and attitude of healthcare providers will determine how satisfied the enrollees will be in the programme (Onuekwusi \& Okpala, 1998; Onoka, Onwujekwe, Uzochukwu \& Ezumah, 2013).

A lot of complaints have trailed the implementation of social health insurance programme in Nigeria (Akeem, Adedoyin \& Olasunmbo, 2014; Ajemunigbonhun, Aduloju, Sogura \& Azeez, 
2017). Enrollees have reported outright denial of healthcare services or payment of additional fees by the healthcare providers on the pretext that the services requested by the enrollees are not included in the benefit packages (Uzochukwu et al., 2015). The enrollees in the social health insurance in Nigeria have reported poor attitudes of some of the healthcare providers in the programme (Osungbade, Obembe \& Oludoyi, 2014; Aremo \& Ibukun, 2017).

The National Health insurance Scheme (2015) operational guidelines stipulates that healthcare providers should be reimbursed fourteen days after submission of claims for services rendered; therefore delays in reimbursement influences healthcare providers' behavior in the programme to a great extent (Dalinjong \& Laar, 2012; Ajemunigbonhun et al., 2017 ). Consequent on delayed reimbursement, healthcare providers are unable to procure drugs and non-drug supplies for the smooth operations of their facilities (Dalinjong \& Laar, 2012). Enrollees that access care at the facilities were made to purchase drugs and non-drug supplies outside the facilities from out of pocket. Other consequence of the delay in reimbursement is that healthcare providers prefer enrollees that would make out of pocket payments for services that are on the benefit package (Ankomah, 2009; Dalinjong \& Laar, 2012; Ajemunigbonhun et al., 2017).

The provider payment mechanism has also been implicated in factors that influence how healthcare providers behave in the health insurance industry (Spaan et al., 2012; Eteng \& Utibe, 2015). Each provider payment mechanism will generate different types of incentives for the healthcare provider with a distribution of financial risk (Spaan et al, 2012). Under the capitation payment mechanism, the healthcare providers receive from HMOs a fixed periodic payment for each enrollee that enrolls in their facility. The import of this is that the healthcare providers therefore face the full financial cost of their enrollee healthcare service use, which then makes the healthcare providers to monitor closely the utilization of healthcare services by the enrollees (Dalinjong \& Laar, 2012; Sodzi-Tettey, Aikins, Awoonor-william \& Agyepong, 2012). This type of payment mechanism will make the healthcare providers be responsible for the enrollees future service use and also as a result will introduce other measures like preventive services so as to reduce cost of healthcare services (Sodzi-Tettey et al., 2012).

However, the healthcare providers that are on fee for service payment mechanism will provide more services because as more services are rendered the more they are paid (Onoka et al., 2013; Onoka, Hanson \& Mills, 2014). Nonetheless, fee for service payment mechanism will lead to healthcare providers encouraging excessive healthcare service utilization and as a result healthcare providers in advanced economies are reimbursed on discounted fee for service basis. Healthcare workers in health facilities will have no incentives to provide more services of any particular type if they are purely on salary payment mechanism.

Moral hazard on the part of the healthcare providers has been a major influence in the extent of provider service supply to enrollees (Onwujekwe, Uzochukwu, Ezeoke \& Uguru, 2011). Generally, providers' moral hazard (supply side moral hazard or supplier - induced demand) involves oversupply of healthcare services sometimes at the prompting of the enrollees who take advantage of the fact that payment for the healthcare services are not made at the point 
of service (POS). Subsequently, the cost of healthcare will be transferred to the health maintenance organization (HMO) (Onwujekwe et al., 2011). Similarly, some moral hazard behaviours that healthcare providers in the health insurance industry exhibits includes; diagnosing simple malaria as complicated malaria, over charging for drugs and services provided to enrollees, charging for services not provided, inflating number of drugs (Dalinjong \& Laar, 2012).

Until, the level of adherence to the stipulations of the operational guidelines is known and also the factors that influence healthcare provider supply of health insurance services are addressed properly by relevant authorities, then there is little possibility of improvement in the quality and supply of services to the enrollees in the programme.

This study therefore tends to examine the adherence of accredited healthcare providers in providing the health insurance services as stipulated in the operational guideline. This will provide evidence-based recommendation on how to improve supply of services in the programme.

\section{Methodology}

\subsection{Study Area}

This research work was carried out in Enugu State. According to the last census before this study, the state has a population of 3,257,298 million with an estimated land mass of 7,618 $\mathrm{km}$ (Nigeria Population Commission, 2006). Six states surround the state and they are: Imo and Abia states on the southern part, Ebonyi state on the Eastern part, Anambra state on the western part while Kogi and Benue states on the Northern part.

\subsection{Study Design}

The study design adopted for this research work is a cross-sectional method with a quantitative (questionnaire) component in exploring the variables in this study. This research design was seen as being most appropriate for this study because it provided reliable and valid data from the respondents on both the demand and supply side of the formal sector social health insurance programme in Enugu state at a given period of time.

\subsection{Population of Study}

The study population were the eighty six thousand $(86,000)$ enrolled individuals on federal government employment working in Enugu state (NHIS Annual report, 2015) whose names are on the hospital register for the past one year and eighty four Chief Medical Directors of accredited healthcare providers operating in Enugu state (NHIS Annual report, 2015).

\subsection{Sample Size}

On the demand side (enrollees), sample size was calculated using G - Power 3.1 software. This approach is justified here because it will determine the smallest sample size that is suitable to detect the effect of a given variable at the desired level of significance. An adequate minimum sample size of 1292 was computed based on $95 \%$ confidence interval and power of $95 \%$. However in order to take care of non-response rate or attrition, the sample size 
was increased by $10 \%$, thus giving us a total sample size of 1435 .

On the supply side (providers), the sample size was calculated using Cochran's formula (Cochran, 1977). This formula is indicative here because much information is not known about the opinion of the healthcare providers on the health insurance services they provide in the programme and as a result maximum variability is desired. An adequate minimum sample size of 42 was computed using estimated population proportion of 0.5 at $95 \%$ confidence interval. In order to take care of attrition, the sample size was increased by $10 \%$, thus giving us a total sample size of 46 .

\subsection{Inclusion Criteria}

- Enrolled respondents whose names appeared on the hospital list.

- Enrolled in the formal sector social health insurance programme for one year.

- Enrollees who have been using the NHIS accredited healthcare provider for one year.

- Healthcare providers that have NHIS accreditation for one year.

- Willingness to participate in the study.

\subsection{Sampling Procedure}

A total of five government hospitals, four mission hospitals and seventy five private hospitals are accredited in the state. A multi-stage sampling technique was adopted in the selection. The first stage involved stratifying the hospitals into three groups (government - owned, mission owned, private - owned). The government hospitals have a total of 58,000 enrollees, mission hospitals have a total of 19,000 enrollees while the private hospitals have a total of 9,000 enrollees. The study population is 86,000 enrollees on the demand side. The sample size of one thousand four hundred and thirty five (1435) respondents was allocated proportionately among the randomly selected Government hospital (968), Mission hospitals (317) and private hospitals (150). The proportion allocated was gotten using the formula; sample fraction (sample size divided by study population) times relative sizes of each stratum.

The second stage involved the use of simple random technique to select one hospital from each group where samples were drawn. The randomly selected government - owned hospital has 34,790 enrollees and all the allocated proportion was selected from it, the mission owned hospital selected randomly has 10,800 enrollees and all the allocated proportion was selected from it while the first privately - owned hospital selected randomly has 42 enrollees. A second privately - owned hospital with 1080 enrollees was selected randomly from the privately-owned hospitals and the remaining sample allocated to them was drawn from it.

The third stage involved the use of systematic sampling technique to select the respondents for the study. Here, the selection in each stratum was every $60^{\text {th }}$ enrollee (as indicated in the attendance sheet) who visited the clinics on the days of the study (sample size in each stratum divided by the population in each stratum). However, the first enrollee in each stratum was selected by simple random sampling technique. 


\section{Al Macrothink}

Journal of Public Administration and Governance

ISSN 2161-7104

2019, Vol. 9, No. 3

On the supply side, a multistage approach was adopted too. The hospitals were stratified into government-owned, privately-owned and mission-owned. The Chief Medical Directors (CMDs) in government - owned hospitals were 5, the CMDs in private hospitals were 75 and in mission hospitals, the CMDs were 4. A minimum sample size of 46 Chief Medical Directors was proportionately allocated to the stratified hospitals using the formula; sample fraction (sample size divided by study population) times relative sizes of each stratum and the followings were therefore allocated; privately-owned -41 , government-owned -3 and mission-owned -2 . Thereafter, simple random was used to select allocated proportion in each stratum for the study.

\subsection{Method of Data Analysis}

On analysis, the data were descriptively analyzed using percentages, mean and standard deviations. Further on analysis, the test value or standard operational guideline (pass mark) was benchmarked at $75 \%$ (there was no previous studies to be used for benchmarking). It should be noted that all the 10 indicators variables (questions) were scored in order to generate a continuous variable (in this case referred to as Operational guideline score for Consumer and Healthcare provider (scored in \%) using this equation:

Operational Guideline $($ scored $)=\frac{\text { sum of all the variables }}{40} \times 100 \%$

Here, the value, 40 represents the mark a respondent would have scored supposing he/she answered strongly agreed for all the 10 variables. Note the following ranking: Strongly Agreed $=4$, Agreed $=3$, Disagree $=2$, Strongly Disagreed $=1$ was used to weight the responses. T- Test was therefore used to test whether the provider performance and enrollee expectation were different from the standard operational guideline. Statistical significance was set at $p<0.05$. Data were analyzed using SPSS version 20 (IBM, New York, USA).

\section{Results}

Out of the 1481 questionnaires administered to both the enrollees and the providers, the return rate was $99 \%$ (enrollees) and $91 \%$ (healthcare providers). The results are presented below

Table 1. Enrollee's/Provider's Response on Provision of Services

\begin{tabular}{|c|c|c|c|c|c|c|c|c|c|c|}
\hline \multirow[t]{2}{*}{ Variables } & \multirow{2}{*}{$\begin{array}{l}\text { Enrollees; } \\
\text { SA }\end{array}$} & \multicolumn{3}{|l|}{$\mathrm{n}=1426$} & \multicolumn{4}{|c|}{ Providers; $\mathrm{n}=42$} & \multirow{2}{*}{ Enrollees } & \multirow{2}{*}{ Providers } \\
\hline & & A & $\mathrm{D}$ & SD & SA & $\mathrm{A}$ & $\mathrm{D}$ & SD & & \\
\hline $\begin{array}{l}\text { Health provider } \\
\text { offer } 24 \text { hours } \\
\text { services }\end{array}$ & $720(50.5)$ & $528(37.0)$ & $128(9.0)$ & $50(3.5)$ & $30(71.4)$ & $12(28.6)$ & $0(0.0)$ & $0(0.0)$ & $3.35(0.79)$ & $3.71(0.46)$ \\
\hline $\begin{array}{l}\text { Laboratory } \\
\text { services are } \\
\text { offered in the } \\
\text { hospital }\end{array}$ & $50(3.5)$ & $22(1.5)$ & $1152(80.8)$ & $202(14.2)$ & $28(66.7)$ & $14(33.3)$ & $0(0.0)$ & $0(0.0)$ & $1.94(0.54)$ & $1.33(0.48)$ \\
\hline $\begin{array}{l}\text { Emergency } \\
\text { services are } \\
\text { offered by the } \\
\text { health provider }\end{array}$ & $20(1.4)$ & $15(1.1)$ & $210(14.7)$ & $1181(82.8)$ & $30(71.4)$ & $12(28.6)$ & $0(0.0)$ & $0(0.0)$ & $1.21(0.52)$ & $3.71(0.46)$ \\
\hline
\end{tabular}




\begin{tabular}{|c|c|c|c|c|c|c|c|c|c|c|}
\hline $\begin{array}{l}\text { Health provider } \\
\text { offer admission } \\
\text { services }\end{array}$ & $24(1.7)$ & $102(7.2)$ & 1294(90.7) & $6(0.4)$ & $40(95.2)$ & $2(4.8)$ & $0(0.0)$ & $0(0.0)$ & $2.1(0.36)$ & $3.95(0.22)$ \\
\hline $\begin{array}{l}\text { Health provider } \\
\text { refer enrollees } \\
\text { for secondary } \\
\text { and tertiary care } \\
\text { promptly }\end{array}$ & $4(0.3)$ & $128(9.0)$ & $1282(89.9)$ & $12(0.8)$ & $37(88.1)$ & $\begin{array}{l}5 \\
(11.9)\end{array}$ & $0(0.0)$ & $0(0.0)$ & $2.09(0.32)$ & $3.88(0.33)$ \\
\hline $\begin{array}{l}\text { Health provider } \\
\text { provide all the } \\
\text { prescribed drugs }\end{array}$ & $20(1.4)$ & $4(0.3)$ & $100(7.0)$ & 1302(91.3) & $4(9.5)$ & $6(14.3)$ & $12(28.6)$ & $\begin{array}{l}20 \\
(47.6)\end{array}$ & $1.12(0.44)$ & $\begin{array}{l}3.14 \\
(1.00)\end{array}$ \\
\hline $\begin{array}{l}\text { Health provider } \\
\text { is politeness } \\
\text { during provision } \\
\text { of services }\end{array}$ & $421(29.5)$ & $962(67.5)$ & $30(2.1)$ & $13(0.9)$ & $\begin{array}{l}29 \\
(69.0)\end{array}$ & $\begin{array}{l}13 \\
(31.0)\end{array}$ & $0(0.0)$ & $\begin{array}{l}0 \\
(0.0)\end{array}$ & $3.26(0.54)$ & $\begin{array}{l}3.69 \\
(0.47)\end{array}$ \\
\hline $\begin{array}{l}\text { Health provider } \\
\text { possess the } \\
\text { required medical } \\
\text { skills to provide } \\
\text { the required } \\
\text { services }\end{array}$ & $302(21.2)$ & $1103(77.3)$ & $13(0.9)$ & $8(0.6)$ & $\begin{array}{l}30 \\
(71.4)\end{array}$ & $\begin{array}{l}12 \\
(28.6)\end{array}$ & $0(0.0)$ & $\begin{array}{l}0 \\
(0.0)\end{array}$ & $3.19(0.45)$ & $\begin{array}{l}3.29 \\
(0.46)\end{array}$ \\
\hline $\begin{array}{l}\text { Health provider } \\
\text { understand the } \\
\text { plight of the } \\
\text { enrollees while } \\
\text { providing } \\
\text { services }\end{array}$ & $450(31.6)$ & $940(65.9)$ & $20(1.4)$ & $16(1.1)$ & $\begin{array}{l}12 \\
(28.6)\end{array}$ & $8(19.0)$ & $12(28.6)$ & $\begin{array}{l}10 \\
(23.8)\end{array}$ & $3.28(0.54)$ & $\begin{array}{l}2.48 \\
(1.15)\end{array}$ \\
\hline \multirow[t]{2}{*}{$\begin{array}{l}\text { Health provider } \\
\text { attend to health } \\
\text { insurance } \\
\text { enrollees } \\
\text { promptly }\end{array}$} & $32(2.2)$ & $20(1.4)$ & $1124(78.8)$ & $250(17.5)$ & $2(4.8)$ & $\begin{array}{l}18 \\
(42.9)\end{array}$ & $14(33.3)$ & $\begin{array}{l}8 \\
(19.0)\end{array}$ & $1.88(0.52)$ & $\begin{array}{l}2.67 \\
(0.85)\end{array}$ \\
\hline & & & & & & & $\begin{array}{l}\text { Grand } \\
\text { Mean } \\
\text { Deviation }\end{array}$ & $\begin{array}{l}\text { Overall } \\
\text { Standard }\end{array}$ & $2.342(0.50)$ & $3.19(0.59)$ \\
\hline
\end{tabular}

Source: Field survey, 2018.

The table above showed that out of 1426 respondents $720(50.5 \%)$ agreed that healthcare providers offer 24 hour services while none of the Chief Medical Directors disagreed. On referral to secondary and tertiary healthcare facilities only $4(0.3 \%)$ of the enrollees strongly agreed while none of the healthcare providers disagreed. The findings in the study showed that on being polite during provision of services, majority $962(67.5 \%)$ of the respondents on the demand side agreed while on the supply side majority 29 (69.0\%) strongly agreed. On the question of whether the healthcare providers attends to enrollees on health insurance promptly, majority 1124 (78.8\%) of the enrollees disagreed while very few $2(4.8 \%)$ of the healthcare providers strongly agreed. The result therefore showed variation in the opinions of both the consumers (enrollees) and the healthcare providers in most of the variables tested.

Table 2. One Sample t-test for both Consumers and Providers level of adherence to NHIS operational guideline

\begin{tabular}{l|l|l|l}
\hline \multirow{2}{*}{ Variables } & \multicolumn{3}{|c}{ Test Value $=75.00$} \\
\cline { 2 - 4 } & $\mathrm{T}$ & Mean $(\mathrm{SD})$ & $\mathrm{p}$-value \\
\hline Operational guideline for Enrollees $(\mathrm{n}=1426)$ & -70.81 & $57.71(9.22)$ & 0.000 \\
Operational guideline for Providers $(\mathrm{n}=42)$ & 2.40 & $79.64(12.54)$ & 0.021 \\
\hline
\end{tabular}


Source: Field survey, 2018.

T-test was used to test whether the providers' performance and consumers' expectation were difference from the standard operational guidelines. In this analysis, the variables used to determine the two group means were Operational Guideline (scored), and the test value (standard value). The test value of $75 \%$ was used as the standard operational guideline (benchmark) and was compared with the responses from the provider and enrollee side which is referred to as Operational Guideline (scored) of the consumers.

The operational guideline for the consumer showed the t-value of -70.814 , which is statistically significant $(\mathrm{p}<0.05)$. Therefore, we can conclude from the consumers' side that the healthcare providers' performance in the programme is not far from the standard operational guideline.

Also, the $t$ value of $2.400(\mathrm{p}<.05)$ obtained from a t-test conducted using the operational guideline for the providers revealed that the healthcare providers' performance is significantly not far from the standard operational guideline. Therefore, we can conclude that the healthcare providers in the programme adhere to the stipulations of the operational guidelines of the Scheme.

\section{Discussion}

The findings in this study showed that only $4.0 \%$ of the enrollees sampled in this study agreed that the healthcare providers provide laboratory services as stipulated in the operational guideline. This is in contrast to the findings of Daramola, Maduka, Adeniran and Akande (2017) and Mitiku and Geberetsadik (2019) that showed in their various studies that majority of their respondents expressed high level of satisfaction with laboratory services and it was attributed to laboratory staff attitude and timeliness of results. Likewise, only $2.5 \%$ of the enrollees agreed that the healthcare providers provide emergency services in the programme. This notion of the enrollees in this study concurs with the findings as shown in the study done by Agba (2010) where majority (62\%) of the respondents indicated non provision of emergency services by the healthcare providers in the programme and $26 \%$ of the respondents rated the quality of services provided as being very poor while $37 \%$ indicated that the programme has not impacted in their health status, $14 \%$ of the respondents were undecided. Similarly, Osuchukwu et al. (2013) showed in their finding that $68 \%$ of the respondents in their study strongly agreed that the services rendered in the programme have not measured up with the standard stipulated in the operational guideline.

On provision of 24 hours healthcare services, the findings in this study showed that $87 \%$ of the enrollees sampled agreed that healthcare providers offer 24 hours services in their facilities. This is affirmed by all (100\%) of the healthcare providers sampled in this study. The findings in this study therefore tallies with the responses of the respondents in Akeem et al. (2014) study which showed that $60 \%$ of them indicated preference to accessing healthcare facilities for health insurance services because of the quality of services rendered.

Healthcare provider provision of prescribed drugs have been shown in several studies to be an indication of quality service (O'Malley, Fletcher, Fletcher \& Earp, 1993; Brawley, 2000; 
Akande, Omotosho \& Nurudeen, 2005) The findings in this study revealed that $91 \%$ of the enrollees strongly disagreed that the providers provide all the prescribed drugs and this concurs with the findings in Agba (2010) that showed 48\% of their respondents strongly agreed that prescribed drugs are given to enrollees as stipulated in the guideline. Similar studies in Mozambique (Newman, Gloyd, Nyangez \& Machoro, 1998) and Nigeria (Daramola et al., 2019) have indicated that non provision of prescribed drugs was found to be the most common complaints from enrollees. However, the findings in this study contradicts Osungbade, Obembe and Oludoyi (2014) findings that showed 55.6\% of their respondents were satisfied with the availability of prescribed drugs. Also, it is in contrast with the opinion of the sampled providers in this study that strongly agreed (47.6\%) and agreed (28.6\%) respectively that the healthcare providers provide all the prescribed drugs. The variance in the opinion of the healthcare providers and the enrollees in this study might be because the healthcare providers might not want to be perceived as not living upto their Hippocratic Oath of caring for human lives first before any other thing.

According to National Health Insurance Scheme operational guideline (2012), all authorization for referral is given within $24 \mathrm{hrs}$ of the requesting facility making contact with the HMO. The findings in this study showed that the enrollees (91\%) strongly agreed that health providers do not refer enrollees for secondary and tertiary care but it contradicts the findings of Mohammed, Bermejo, Souares, Sauerborn and Dong (2014) that showed that less than half of their respondents $(45.6 \%)$ have never been referred for secondary or tertiary care and also the opinion of the healthcare providers sampled in this study (88\%) who strongly agreed that enrollees were referred appropriately for secondary and tertiary care. The contradictions in the two findings might be due to the fact that Mohammed et al. (2014) study was carried out in a secondary center where referrals are done internally and as a result incentives are there for the referral while in this study, it was carried out in primary, secondary and tertiary centers.

Several studies (Abdosh, 2006; Iliyasu, Abubakar, Abubakar, Lawan \& Gajida, 2010) have revealed that healthcare provider attitude while providing services influences enrollees' level of satisfaction. In this study, there was unanimous agreement among the enrollees and the healthcare providers that the attitude of the providers towards the enrollees were encouraging. Majority of the enrollees (69\%) and majority of the health providers (65.9\%) agreed that the healthcare providers were polite during provision of services and similarly, majority of the respondents on both demand and supply side also agreed that the health providers understood the plight of the enrollees during provision of services. The opinion of the enrollees in this study tallies with that of the healthcare providers sampled in this study with regard to providers' politeness to enrollee in the course of rendering healthcare services. Here, majority of the providers agreed that providers were polite to the enrollees and this finding concurs with Osungbade et al (2014) study that showed $57.1 \%$ of the participants were highly satisfied with the staff attitude.

The findings in the study revealed that majority of the enrollees (78.8\%) disagreed that health providers attend to health insurance enrollees promptly. This finding is consistent with the findings in Nigeria (Mohammed et al., 2014; Daramola et al., 2017) and Ethiopia (Mitiku \& 
Geberetsadik, 2019) that showed most of the participants strongly disagreed that they were attended to promptly. This might be due to delays occasioned by improper identification of the enrollees and it might be attributed to non-provision of proper identification card. However, in contrast, most of the providers sampled agreed (33.3\%) and strongly agreed that enrollees in the health insurance programme were promptly attended to during the time they access health services.

Finally, the aggregated opinions of the providers and enrollees in the programme showed that the providers service provision were not far from what is stipulated in the NHIS operational guideline and this findings tallies with the work done by Osungbade et al. (2014) and Akeem et al. (2014) which showed that respondents in their respective studies were highly satisfied with the providers' provision of services in social health insurance program as stipulated by the regulatory body.

\section{Conclusion}

This study reveals that the most of enrollees believes that the providers of health insurance services do not provide laboratory services, prescribed drugs, emergency services and referral of enrollees to secondary and tertiary facilities. However, it was shown in the study that majority of the enrollees and providers agreed that the healthcare providers provide 24 hour services and were polite and empathic to enrollee plight. Similarly, on the aggregation of the opinions of both the provider and enrollees in the programme, it was discovered that the provider service provision was not far from what was stipulated in the operational guideline. The findings in this study will therefore serve as an implementation tool and guide to policy formulators in future policy revisions and strategic decisions.

\section{Recommendation}

Following the findings of the study and the conclusion arrived from the study, some of the following policy options are recommended:

1. Government should ensure checks that will promote the availability and quality of prescribed drugs.

2. Again, the regulatory body should strengthen the extant polices that will allow for prompt payment of providers and put stricter measures to check HMOs that default in this regard.

3. Also, use of technology (Point of service based machine) should be encouraged to enhance efficiency in the areas of referral, enrolment, claims, identification of enrollees.

4. There should be strictness on quality assurance and removal of accreditation of offending healthcare providers. This will invariably encourage improvement in the supply of health insurance services.

\section{Acknowledgement}

The Authors acknowledge the academic staff of department of Health Administration and 
Management, University of Nigeria Enugu campus

\section{References}

Abdosh, B. (2006). The quality of hospital services in Eastern Ethiopia: patients' perspective. Ethiopian Journal of Health Development, 20, 199-200. https://doi.org/10.4314/ejhd.v20i3.46854

Adibe, M. O., Udeogaranya, P. O., \& Ubaka, C. M. (2011). Awareness of national health insurance scheme activities among employees of a Nigerian university, Int. J. Drug Dev. \& Res, 3(4), 78-85.

Agba, M. S. (2010). Perceived impact of the national health insurance scheme among registered staff in federal polytechnique, Idah, Kogi State. Nigerian Studies in Sociology of Science, 1(1), 44-49.

Ajemunigbonhun, S. A., Aduloju, S. A., Sogura, A. B., \& Azeez, F. T. (2017). Demand for health insurance among individual households in Lagos state: effects of socio-demographic variables. European Journal of Accounting, Financial \& Business, 5, 13.

Akande, T. M., Omotosho, I. M., \& Nurudeen, H. ( 2005). Perception of patients on quality of health care services at a teaching hospital in Ilorin, Nigeria. European Journal of Scientific Research, 11, 1.

Akeem, A. A., Adedoyin, S., \& Olasunmbo, O. (2014). Artisan reactions to national health insurance in Lagos state. Nigeria. Journal of Global Health System, 4, 1-3.

Ankomah, M. (2009). Reforms in the provider tariff for the NHIS: Key implementation issues. NBER working paper series, 12(3), 7206-7209.

Aremo, A. G., \& Ibukun, C. O. (2017). Health insurance and healthcare demand pattern among staff and students of selected universities in Southwestern Nigeria. British Journal of Education, Society \& Behavioural Science, 20(2), 1-13. https://doi.org/10.9734/BJESBS/2017/31799

Awosika, L. (2012). Private health insurance: a pillar towards universal coverage. Health Research Policy and Systems, 7, 18.

Brawley, M. (2000). The client perspective, what is quality health care service. Medwell Journals, 4(2), 143- 148.

Cochran, W. G. (1977).Sampling technique ( ${ }^{\text {rd }}$ ed). New York: John Wiley \& Sons.

Dalinjong, P. A., \& Laar, A. S. (2012). The national health insurance scheme: perceptions and experiences of healthcare providers and clients in two districts of Ghana. Health Economic Review, 2, 13-16. https://doi.org/10.1186/2191-1991-2-13

Daramola, O. E., Maduka, W. E., Adeniran, A., \& Akande, T. M. (2017). Evaluation of patients, satisfaction with service accessed under the national health insurance scheme at a tertiary facility in North Central, Nigeria. Journal of Community Medicine and Primary 
Health Care, 29, 1

Eteng, I. E., \& Utibe, E. E. (2015). The national health insurance scheme and its implication for elderly care in Nigeria. International Journal of Science and Research, 4, 2.

Iliyasu, Z., Abubakar, I. S., Abubakar, S., Lawan, U. M., \& Gajida, A. U. (2010). Patients' satisfaction with services obtained from aminu kano teaching hospital, Kano, Northern Nigeria. Journal of Scientific Research, 11, 1.

Mitiku, K. K., \& Geberetsadik, S. M. (2019). Household satisfaction with community-based health insurance scheme and associated factors in piloted Sheko district, Southwest Ethiopia. Plos One 14(5). https://doi.org/10.1371/journal.pone.0216411

Mohammed, S., Bermejo, J. L., Souares, A., Sauerborn, R., \& Dong, H. (2014).Assessing responsiveness of healthcare services within a healthcare insurance system in Nigeria. BMC Health Services Research, 13(2), 10 -14. https://doi.org/10.1186/1472-6963-13-502

NHIS (2012). Operational Guidelines. Abuja, Nigeria: National Health Insurance Scheme.

NHIS. (2015). Annual report of the national health insurance scheme, Abuja, Nigeria. National Health Insurance Scheme.

NHIS. (2015). National health insurance scheme operational guidelines. Abuja, Nigeria: National Health Insurance Scheme.

NPC. (2006). National census figures. Abuja, Nigeria: National Population Commission.

O'Malley, Fletcher, S., Fletcher, R., \& Earp, J. (1993). Measuring patient waiting time in a practice setting: A comparison of methods. Journal of Ambulatory Care Management, 6, 20. https://doi.org/10.1097/00004479-198308000-00006

Onoka, C. A., Hanson, K., \& Mills, A. (2014). Growth of health maintenance organization in Nigeria and the potential for a role in promoting universal coverage efforts. Social Science and Medicine, 58, $70-74$.

Onoka, C. A., Onwujekwe, O. E., Uzochukwu, B. S., \& Ezumah, N. N. (2013). Promoting universal financial protection: constraints and enabling factors in scaling-up coverage with social health insurance in Nigeria. Health Research Policy and Systems, 11, 20. https://doi.org/10.1186/1478-4505-11-20

Onuekwusi, N., \& Okpala, C. O. (1998): Awareness and perception of the national health insurance scheme (NHIS) among Nigeria healthcare professionals. Journal of College of Medicine, 3(2), 97-99.

Onwujekwe, O. E., Uzochukwu, B. S., Ezeoke, O. P., \& Uguru, N. P. (2011). Health insurance principles, models and the Nigeria national health insurance scheme. International Journal of Medicine and Health Development, 16, 1-3. Retrieved July 14.2016, from www.ajol.info/index.php/jcm/article.

Osuchukwu, N. C., Osonwa, K. O., Eko, J. E., Uwanede, C. C., Abeshi, A., \& Offiong, D. A. 
(2013). Evaluating the impact of national health insurance scheme on healthcare consumers in calabar metropolis, Southern Nigeria. African Journal of Social Science, 3(4), 2164-4063. https://doi.org/10.5296/ijld.v3i4.4242

Osungbade, K. O., Obembe, T. A., \& Oludoyi, A. (2014). Users Satisfaction with Service Provided under National Health Insurance Scheme in South Western Nigeria. International Journal of Tropical Disease and Health, 4(5), 595-607. https://doi.org/10.9734/IJTDH/2014/7280

Sodzi-Tettey, S., Aikins, M., Awoonor-William, J. K., \& Agyepong, I. A. (2012). Challenges in provider payment under the Ghana medical health insurance scheme: a case study of claims management in two districts. Ghana Medical Journal, 48(4), 189-199.

Spaan, E., Mathijssen, J., Tromp, N., Mcbain, F., Ten Have, A., \& Baltussen, R. (2012). The impact of health insurance in Africa and Asia: a systematic review. Bull World Health Organ, 90, 685-92. https://doi.org/10.2471/BLT.12.102301

Uzochukwu, B., Ughasoro, M. D., Etiaba, E., Okwuosa, C., Envuladu, E., \& Onwujekwe, O. E. (2015). Health care financing in Nigeria: implications for achieving universal health coverage. Niger J Clin Pract, 18, 437-44. https://doi.org/10.4103/1119-3077.154196

\section{Copyright Disclaimer}

Copyright for this article is retained by the author(s), with first publication rights granted to the journal.

This is an open-access article distributed under the terms and conditions of the Creative Commons Attribution license (http://creativecommons.org/licenses/by/4.0/). 